\title{
Making mathematical meaning: from preconcepts to pseudoconcepts to concepts
}

\author{
Margot Berger \\ School of Mathematics, University of Witwatersrand \\ mberger@maths.wits.ac.za
}

I argue that Vygotsky's theory of concept formation (1934/1986) is a powerful framework within which to explore how an individual at university level constructs a new mathematical concept. In particular I argue that this theory can be used to explain how idiosyncratic usages of mathematical signs by students (particularly when just introduced to a new mathematical object) get transformed into mathematically acceptable and personally meaningful usages. Related to this, I argue that this theory is able to bridge the divide between an individual's mathematical knowledge and the body of socially sanctioned mathematical knowledge. I also demonstrate an application of the theory to an analysis of a student's activities with a 'new' mathematical object.

\section{Introduction}

The issue of how an individual makes personal meaning of a 'new' mathematical object is a fundamental issue in mathematics education. In particular, at many universities the student is frequently introduced to a new mathematical object through a definition ${ }^{1}$. From this definition, the learner is expected to construct the properties of the object (Tall, 1995). In many instances neither diagrams nor exemplars of the mathematical object are presented alongside the definition; initial access to the mathematical object is through the various signs (such as words and symbols) of the definition.

In this paper I examine how a student at university level makes meaning of a mathematical object presented in the form of a definition. I argue that Vygotsky's theory of preconceptual and pseudoconceptual thinking (1934/1986) provides an appropriate structure within which to explore how a student constructs concepts which are both personally and culturally meaningful. In particular, I show that Vygotsky's theory can be used to explain how idiosyncratic usages by learners of 'new' (to the student) mathematical signs get transformed into mathematically acceptable usages. I illustrate the theory through an example in which we see how a university student makes meaning of a mathematical object introduced through a definition.

My argument revolves around Vygotsky's idea of the functional use of a sign. In terms of this

\footnotetext{
${ }^{1}$ The introduction of new mathematical objects through definitions is common practice in many South African universities and in certain British universities such as Warwick (Alcock and Simpson, 2001).
}

notion, and as I argue later, the learner's use of the mathematical signs in activity and communication is a necessary first step in the appropriation of mathematical meaning. This usage precedes an understanding of the mathematical object signified by the mathematical sign. This argument contradicts the position most mathematics educators take, often implicitly, that understanding and the construction of mathematical meaning needs to occur prior to the use of the symbol.

Although my focus is on how a student at university level makes meaning of a new mathematical object presented in the form of a definition, my arguments also relate to school level mathematics. Understanding the extreme case of a mathematical object introduced through a definition provides a window into what is happening when a learner encounters a new mathematical object, no matter the academic level and no matter that it may be introduced through exemplars and/or with diagrams (as is common practice in many South African high schools).

\section{Background}

Several mathematics education researchers have considered how an individual, at university level, constructs a mathematical concept and some have developed significant theories in response. The most influential of these theories focus on the transformation of a process into an object (for example, Tall, 1995; Dubinsky, 1991; Czarnocha et al., 1999).

According to Tall et al. (2000), the idea of a process-object duality originated in the 1950s in the work of Piaget who spoke of how "actions and 


\section{Margot Berger}

operations become thematized objects of thought or assimilation" (cited in Tall et al., 2000: 1).

In adopting a neo-Piagetian perspective, these researchers and their various followers successfully extend Piaget's work regarding elementary mathematics to advanced mathematical thinking. For example, Czarnocha et al. (1999) theorise that in order to understand a mathematical concept, the learner needs to move between different stages. She has to manipulate previously constructed objects to form actions. "Actions are then interiorised to form processes which are then encapsulated to form objects" (1999: 98). Processes and objects are then organised in schemas. Dubinsky (1991) names this theory APOS (Actions, Process, Object, Schema).

But much of this process-object theory does not resonate with what $\mathrm{I}$ see in my (university) mathematics classroom. For example, it does not help me explain or describe what is happening when a learner fumbles around with 'new' mathematical signs making what appear to be arbitrary connections between these new signs and other apparently unrelated signs. Similarly, it does not explain how these incoherent-seeming activities can lead to usages of mathematical signs that are acceptable to professional members of the mathematical world and personally meaningful to the learner.

I maintain that the central drawback of these neo-Piagetian theories is that they are rooted in a framework in which conceptual understanding is regarded as deriving largely from interiorised actions; the crucial role of language (or signs) and the role of social regulation and the social constitution of the body of mathematical knowledge is not integrated into the theoretical framework. Given that mathematics learning is by its very nature a social activity, mediated and constituted by language, signs and tools (for example, textbooks), a concentration on interiorised actions is problematic. Indeed, meaning, thinking and reasoning need to be seen as products of social activity (Lerman, 2000: 23), not just the characteristics of a decontextualised individual.

In this regard, a framework is required in which the link between an individual's construction of a concept and socially sanctioned knowledge (existing in the community of mathematicians and in reified form in textbooks) is foregrounded. Furthermore, given that mathematics can be regarded as the "quintessential study of abstract sign systems" (Ernest, 1997) and mathematics education as "the study of how persons come to master and use these systems" (ibid.), a framework which postulates semiotic mediation as the mechanism of learning, seems apposite. I claim that Vygotsky's much-neglected notions of preconceptual and pseudoconceptual thinking, allied with a notion of the functional usage of a sign (1934/1986), provide theoretical tools with which the researcher or teacher can make sense of what is happening when a student attempts to construct a new mathematical concept.

\section{Vygotsky's theory of concept formation}

Although Vygotskian theory has been applied extensively in mathematics education, most of the research has focused on the mathematical activities of a group of learners or a dyad rather than the individual (Van der Veer and Valsiner, 1994).

Indeed, Van der Veer and Valsiner claim that the use of Vygotsky in the West has been highly selective. They argue that "the focus on the individual developing person which Vygotsky clearly had ... has been persistently overlooked" (1994: 6; italics in original).

In this paper, I focus on the activities of an individual. My focus on the individual is motivated by the situation at many universities (South Africa and worldwide) in which much learning occurs in the context of an individual sitting with a textbook. (Of course this does not deny that learning may also take place in other settings such as lecture rooms or discussions with other students).

It is important to note that a focus on the individual (possibly with a textbook or lecture notes) does not contradict the fundamental Vygotskian notion that "social relations or relations among people genetically underlie all higher functions and their relationships" (Vygotsky, 1981: 163). After all, a situation consisting of a learner with a text is necessarily social; the textbook or exercises have been written by an expert (and can be regarded as a reification of the expert's ideas); also the text may have been prescribed by the lecturer with pedagogic intent. Thus a focus on the individual does not in any way undermine the significance of the social.

\section{Functional use of the sign}

My understanding of how a student constructs a new mathematical concept is based on Vygotsky's theory of how a child learns the meaning of a new word. In this regard it is important to note that Vygotsky regards a word as embodying a concept.

He postulates that the child uses the 'new' word 
for communication purposes before that child has a fully developed understanding of that word:

Words take over the function of concepts and may serve as means of communication long before they reach the level of concepts characteristic of fully developed thought (Uznadze, cited in Vygotsky, 1934/1986: 101).

The use of a word or sign to refer to an object (real or virtual) prior to 'full' understanding resonates with my sense of how an undergraduate student makes a new mathematical object meaningful to herself. In practice, the student starts communicating with peers, with lecturers or the potential other (when writing) using the signs of the new mathematical object (symbols and words) before she has full comprehension of the mathematical object. It is this usage of the mathematical signs, with the accompanying communication, that gives initial access to the new object.

Secondly Vygotsky argues that the child does not spontaneously develop concepts independent of their meaning in the social world:

He does not choose the meaning of his words... The meaning of the words is given to him in his conversations with adults (Vygotsky, 1934/1986: 122).

Thus the social world, with its already established definitions (as given in dictionaries or books) of different words, determines the way in which the child's understanding of the object needs to develop.

Analogously, I argue that in mathematics, a student is expected to construct a concept whose use and meaning is compatible with its use in the mathematics community.

To do this, that student needs to use the mathematical signs in communication with more knowledgeable others (including using textbooks). Through this usage, which is socially regulated (via the interaction with a text or others), the meaning of a concept can evolve for the learner in a way that is compatible with its culturally accepted usage (Berger, 2004a).

This functional use argument is reminiscent of Dörfler's (2000) thesis that in order to appropriate a new mathematical object, the mathematics student has to be willing to adopt an attitude whereby he participates in the discourse of mathematics as-if the discourse is meaningful and coherent, even if he does not experience it as such.

It is also supported by Pimm's (1987) argument about the importance of learners' mathematical talk, no matter the impreciseness of this talk.
Once something is expressed, however haltingly and incompletely, then questions can be asked about the current formulation in order to encourage greater refinement, precision and clarity. (ibid.: 31)

\section{Semiotic mediation}

Vygotsky (1978) regarded all higher human mental functions as products of mediated activity. The role of the mediator is played by a psychological tool or sign, such as words, graphs, algebra symbols, or a physical tool. These forms of mediation, which are themselves products of the socio-historical context, do not just facilitate activity; they define and shape inner processes. According to Vygotsky, action mediated by signs is the fundamental mechanism which links the external social world to internal human mental processes and he argues that it is

by mastering semiotically mediated processes and categories in social interaction that human consciousness is formed in the individual (Wertsch and Stone, 1985: 166).

Allied to this, concept formation, as discussed above, is only possible because the word or mathematical object can be expressed and communicated via a word or sign whose meaning is already established in the social world.

In mathematics, the same mathematical signs mediate two processes: the development of a mathematical concept in the individual and that individual's interaction with the already codified and socially sanctioned mathematical world (Radford, 2000). In this way, the individual's mathematical knowledge is both cognitively and socially constituted.

This dual role of a mathematical sign by a learner before 'full' understanding is not well recognised by the mathematics education community; indeed, its manifestations in the form of activities such as manipulations, imitations and associations are often not appreciated by mathematics educators. $^{2}$ For example, certain proponents of the Calculus Reform Movement believe that mathematical skills are somehow separate from understandings. As Ganter (2001: 23) puts it: what is "being debated are which basic mathematical computations and skills should go along with conceptual understanding" (my italics), as if conceptual understandings were somehow

\footnotetext{
2 An exception to this is Sfard (2000) whose theory of templatedriven use implies use of symbols before understanding of mathematical objects.
} 


\section{Margot Berger}

independent of computations and skills. Seldon and Seldon (2001) describe, without any hint of misgiving, how textbooks used by the ACE Teaching Cycle which is based on APOS Theory, contain no template solutions to problems. They do not even seem to consider that imitation may play an important role in learning.

Vygotsky's theory, that usages of the sign are a necessary, but not sufficient, part of concept formation, manages to provide a link between certain types of mathematical activities (including those activities frequently ignored or regarded pejoratively by mathematics educators) and the formation of concepts. For this reason, it has great implications for desirable pedagogical practices. ${ }^{3}$

\section{Different preconceptual stages}

Vygotsky elaborated his theory by detailing the stages in the formation of a concept. He claimed that the formation of a concept entails the learner moving through different preconceptual stages (heaps, complexes and potential concepts).

According to Kozulin (1990: 159), Vygotsky's position was that these

preconceptual types of representation are retained by older children and adults, who quite often revert to these more 'primitive' forms depending on their interpretation of a given task and on their chosen strategy for solution.

It is in this latter sense that I maintain that university mathematics students use preconceptual (that is, heap and complex) thinking when dealing with new ideas. Most importantly, this movement is not linear. Indeed the learner may move back and forth between the different stages.

During the syncretic heap stage, the child groups together objects or ideas which are objectively unrelated. This grouping takes place according to chance, circumstance or subjective impressions in the child's mind. For example, a learner is using heap thinking if she interprets, say, the meaning of a mathematical sign based on the layout of the page.

In the complex thinking stage, the learner's activities are driven by non-logical activities such as template-matching, associations, imitation, manipulations, etc. As a result, complex thinking

\footnotetext{
${ }^{3}$ It is important to stress that, in terms of the above theory and in contrast to the back-to-basics position, adequate use of a mathematical sign is not sufficient evidence of a student's understanding of the relevant mathematical concept.
}

often manifests as an idiosyncratic usage of mathematical signs.

An example of complex thinking using association is as follows: On first encountering the derivative, $f^{\prime}(x)$, of a function $f(x)$, many learners associate the properties of $f^{\prime}(x)$ with the properties of $f(x)$. Accordingly, these learners assume that since $f(x)$ is continuous, so is $f^{\prime}(x)$. Clearly this is not logical; indeed it is mathematically incorrect.

An example of activity guided by complex thinking using template-matching (Sfard, 2000) is when the student uses the template $\frac{a}{a}=1, a \in \square$ to argue that $\frac{0}{0}=1$, which is, of course incorrect. However the argument that, say, $\frac{\sqrt{3}}{\sqrt{3}}=1$, is correct (and may also be based on templatematching).

But my point right now is not how the student uses the signs but rather that she uses the signs. Through this use, the student gains access to the 'new' mathematical object and is able to communicate (to better or worse effect) about it. And, as I have just argued, it is this communication with more knowledgeable others which enables the development of a personally meaningful concept whose use is congruent with its use by the wider mathematical community.

My observations of undergraduate students over the years ties in very well with the idea that preconceptual thinking is a necessary part of successful mathematical concept construction.

With regard to potential concepts, Vygotsky (1934/1986: 135) argues that complex thinking creates the basis for later generalisations in that the learner classifies different objects into groups (or complexes) on the basis of particular characteristics. However, classification would not be possible without abstraction of these particular characteristics. Thus the learner engages in abstractions concurrently with complex thinking. Vygotsky calls the formation that results from the grouping together of objects on the basis of a single attribute or a set of attributes, a 'potential concept'.

Abstractions are inherent in the construction of any mathematical concept and so potential concepts in the Vygotskian sense abound in mathematical thinking. But the abstraction of attributes is so profoundly intertwined with the formation of complexes in advanced mathematical thinking that it is impossible to distinguish 
potential concepts from mathematical complexes. For this reason I suggest that the potential concept is not a particularly useful or appropriate category of analysis, particularly in the advanced mathematical domain.

Vygotsky distinguishes between five different types of complexes. I will not go into detail here about the different forms and indicators of complex thinking in the mathematical domain. (For such an elaboration, see Berger, 2004b, 2004c.) Suffice to note that complex thinking manifests as a non-logical usage of signs, as discussed above.

However, I will elaborate on the pseudoconcept since this construct provides a bridge between preconceptual (i.e. complex) and conceptual thinking.

\section{The pseudoconcept: a bridge between the individual and the social}

At this juncture, we need to establish what Vygotsky meant by conceptual thinking. In conceptual thinking, the links between properties and aspects of the concept and between different concepts are logical and the ideas form part of a culturally-recognised and consistent system of hierarchical knowledge. This differs from complex thinking where non-logical thinking predominates.

But how does the transition from complexes to concepts take place? According to Vygotsky, it is through the use of pseudoconcepts.

Pseudoconcepts have a dual nature. That is, they resemble true concepts in their appearance, but the thinking behind the pseudoconcept is still complex in character. That is, with complex thinking, the student is still using association, template-matching or imitation and they may even hold contradictory ideas about the one concept. But, importantly, the learner is able to use the pseudoconcept in communication and activities as if it were a true concept.

The use of pseudoconcepts is ubiquitous in mathematics and is analogous to the use by a child of a word in conversation with an adult before the child fully understands the meaning of that word. Pseudoconcepts occur whenever a student uses a particular mathematical object in a way that coincides with the use of a genuine concept, even though the student has not fully constructed that concept for herself. For example, a student may use the definition of the derivative of a function to compute the derivative of the function before she 'understands' the nature of the derivative or its properties.

Vygotsky (1934/1986) argues that the use of pseudoconcepts enables children to communicate effectively with adults and that this communication is necessary for the transformation of the complex into a genuine concept.

Verbal communication with adults (...) become[s] a powerful factor in the development of the child's concepts. The transition from thinking in complexes to thinking in concepts passes unnoticed by the child because his pseudoconcepts already coincide in content with adult concepts (Vygotsky, 1934/1986: 123).

Thus the pseudoconcept functions as the bridge between concepts whose meaning is more or less fixed and constant in the social world (such as that body of knowledge we call mathematics) and the learner's need to make and shape these concepts so that they become personally meaningful.

In this way, the pseudoconcept can be regarded as a link between the individual and the social. Furthermore, the notion of the pseudoconcept is entirely consistent with the functional use of a sign.

The pseudoconcept can be used to explain how the student is able to use mathematical signs (in algorithms, definitions, theorems, problem-solving, and so on) in effective ways that are commensurate with that of the mathematical community even though the student may not fully 'understand' the mathematical object. The hope is that through appropriate use and social interventions, the pseudoconcept will get transformed into a concept.

\section{Brief demonstration}

I will use the above theory to explain how a firstyear mathematics major student at a South African university moves from an idiosyncratic usage of signs (using, I claim, preconceptual thinking) to a conceptual (or perhaps pseudoconceptual) usage of signs.

The activity took place during an interview which I conducted, video-taped and later transcribed and analysed in 2002 (Berger, 2002).

John had been given the following definition which he has not seen before, although he is familiar with the definite integral and the notion of a limit. 


\section{Margot Berger}

Definition of an improper integral with an infinite integration limit

If $f$ is continuous on the interval $[a, \infty)$, then

$$
\int_{a}^{\infty} f(x) d x=\lim _{b \rightarrow \infty} \int_{a}^{b} f(x) d x
$$

If $\lim _{b \rightarrow \infty} \int_{a}^{b} f(x) d x$ exists, we say that the improper integral converges. Otherwise the improper integral diverges.

This is followed by several questions each of which is presented on its own, in order (for example, John has not seen Question 4 when he first encounters, say, Question 1).

1. (a) Can you make up an example of an improper integral with an infinite integration limit?

1. (b) Can you make up an example of a convergent improper integral with an infinite integration limit?

:

4. Determine whether $\int_{1}^{\infty} \frac{d x}{x^{3}}$ converges or diverges.

John's response, in part, to Question 1(a) is to generate a string of signifiers:

$$
\int_{0}^{\infty} f(x) d x=\lim _{2 \rightarrow \infty} \int_{0}^{2} f(x) d x=\lim _{2 \rightarrow \infty} \int_{0}^{2} \sqrt{x} d x=\int_{0}^{2} \sqrt{x} d x
$$

Clearly what John has written is objectively meaningless and inconsistent.

But the point is that John is using the new mathematical signs in mathematical activities (incoherent as they are to the outsider).

In response to Question 1(b), he writes:

$$
\lim _{2 \rightarrow \infty} \int_{0}^{2} f(x) d x=\lim _{2 \rightarrow \infty} \int_{0}^{\infty} \sqrt{x} d x=\int_{0}^{\infty} \sqrt{x} d x
$$

Again his response appears incoherent and confused. But once more John is using the 'new' (to him) signs in mathematical activities.

I suggest that notions of complex thinking can help the educator understand what is happening. Specifically, I suggest that John's response to both Question 1(a) and 1(b) is dominated by complex thinking. In Question 1(a) he has manipulated the template of an improper integral so that it eventually has the form of a definite integral (i.e. $\int_{0}^{2} \sqrt{x} d x$ ), a form with which he is familiar. In

Question 1(b), he manipulates this further to get back to the template of an improper integral (albeit it does not converge).
The point is: by using various signs in mathematical activities (a functional usage involving template-matching, associations and manipulations primarily) John is able to engage with the mathematical object on first contact, albeit in an idiosyncratic fashion. In this way, John gains a point of entry into mathematical activities with the object before he 'knows' that object.

The question now is: how does John move from this (objectively) incoherent usage to a usage which is both personally satisfying and mathematically acceptable?

I suggest that the answer lies in John's imitation of the improper integral sign. That is, John is finally able to appropriate the socially-sanctioned usage of the improper integral sign through interaction with the mathematics textbook (a resource comprising socially sanctified mathematics).

Specifically, it is only after John has seen exemplars in the textbook of improper integrals and their evaluation, that he starts to use the improper integral in a way that is consonant with its definition. Indeed, after seeing textbook exemplars, he is able to answer Question 4 in a coherent fashion. That is, he writes

$\int_{1}^{\infty} \frac{d x}{x^{3}}=\lim _{b \rightarrow \infty} \int_{1}^{b} \frac{d x}{x^{3}}=\lim _{b \rightarrow \infty}\left[\frac{-2}{x^{2}}\right]_{1}^{b}=\lim _{b \rightarrow \infty}\left[\frac{-2}{b^{2}}-2\right]=-2$.

And he states that this integral is convergent.

Although John has integrated $\int \frac{d x}{x^{3}}$ incorrectly, $\left(\int \frac{d x}{x^{3}}=\frac{-1}{2 x^{2}}\right)$, his response is coherent; also he uses correct procedure and appropriate notation. This is a much improved response compared to his response to Question 1.

Furthermore, John tells me that the examples are useful to him and that he is no longer confused. This contrasts with earlier statements that he is very confused about notions of convergence and divergence and the improper integral.

My contention is: it is John's functional use of the improper integral sign (initially association, template-matching and manipulations and then imitation) that enables him to move from activity dominated by complex thinking to conceptual (possibly pseudoconceptual) activity. Allied to this, he is able to move from a confused notion of the improper integral (by his own admission) to a personally meaningful usage (again, in terms of his own assessment). 


\section{Conclusion}

In this paper, I have argued that Vygotsky's theory of preconceptual and pseudoconceptual thinking (1934/1986) provides an appropriate framework within which to explore how students construct concepts which are both personally and culturally meaningful.

In particular, I have argued that the notion of the functional usage of a sign (that is, the use of a mathematical sign prior to full understanding of the mathematical object that it signifies) together with the construct of the pseudoconcept, can be used to explain how the divide between an individual's initial mathematical activities and a socially sanctioned mathematical definition is bridged. Related to this, I have argued that idiosyncratic mathematical activities can be regarded as manifestations of complex thinking. With social regulation, these complexes can be transformed into pseudoconcepts and (through further activities and further social regulation) concepts.

Given that so many activities that constitute the functional usage of a sign (for example, manipulations, imitations, associations and template-matching) are dismissed or ignored by many mathematics educators, I suggest the need for research which explores the relationships between these different usages of signs and meaning-making. Similarly, research that illuminates the bridges between personal and socially sanctified usages of mathematical signs, and that explicates the transformations from complexes to pseudoconcepts to concepts, is required.

\section{References}

Alcock, L. \& Simpson, A. (2001). The Warwick Analysis Project: Practice and Theory. In D. Holton (Ed.), The Teaching and Learning of Mathematics at University Level: An ICMI Study (pp 99-111). Dordrecht: Kluwer Academic Publishers.

Berger, M. (2002). The Appropriation of Mathematical Objects by Undergraduate Mathematics Students: A study. Unpublished doctoral dissertation, University of the Witwatersrand, Johannesburg.

Berger, M. (2004a). The functional use of a mathematical sign. Educational Studies in Mathematics, 55, 81-102.

Berger, M. (2004b). Heaps, complexes and concepts (part 1). For the Learning of Mathematics, 24 (2), 2-6.
Berger, M. (2004c). Heaps, complexes and concepts (part 2). For the Learning of Mathematics, 24 (3), 11-17.

Czarnocha, B., Dubinsky, E., Prabhu, V. and Vidakovic, D. (1999). One theoretical perspective in undergraduate mathematics education research. In 0. Zaslavsky (Ed.), Proceedings of the $23^{\text {rd }}$ Conference of the International Group for the Psychology of Mathematics Education, (Vol. 1, pp 95-110). Haifa, Israel: PME.

Dörfler, W. (2000). Means for meaning. In P. Cobb, E. Yackel, and K. McClain (Eds.), Symbolizing and Communicating in Mathematics Classrooms: Perspectives on Discourse, Tools, and Instructional Design (pp 99-132). Mahwah, NJ: Lawrence Erlbaum.

Dubinsky, E. (1991). Reflective abstraction in advanced mathematical thinking. In D. Tall (Ed.), Advanced Mathematical Thinking (pp 95123). Dordrecht: Kluwer Academic Publishers.

Ernest, P. (1997). Introduction: Semiotics, Mathematics and Mathematics Education. Philosophy of Mathematics Education, Journal 10. Retrieved December 9, 2000, from http://www.ex.ac.uk/ PErnest/pome10/art1.htm

Ganter, S.L. (2001). Changing Calculus: A report on Evaluation Efforts and National Impact from 1988-1998, MAA Notes \#56. Washington DC: Mathematical Association of America.

Kozulin, A. (1990). Vygotsky's Psychology: A Biography of Ideas. Cambridge, MA: Harvard University Press.

Lerman, S. (2000). The social turn in mathematics education research. In J. Boaler (Ed.), Multiple Perspectives on Mathematics Teaching and Learning (pp 19-44). Westport, CT: Ablex Publishing.

Pimm, D. (1987). Speaking Mathematically: Communication in Mathematics Classrooms. London: Routledge \& Kegan.

Radford, L. (2000). Signs and meanings in students' emergent algebraic thinking: A semiotic analysis. Educational Studies in Mathematics 42, 237-268.

Seldon, A. and Seldon, J. (2001). Tertiary mathematics education research and its future. In D. Holton (Ed.), The Teaching and Learning of Mathematics at University Level: An ICMI Study ( $\mathrm{pp}$ 237-254). Dordrecht: Kluwer Academic Publishers.

Sfard, A. (2000). Symbolizing mathematical reality into being - or how mathematical discourse and mathematical objects create each other. In P. Cobb, E. Yackel, and K. McClain (Eds.), 


\section{Margot Berger}

Symbolizing and Communicating in Mathematics Classrooms: Perspectives on Discourse, Tools, and Instructional Design (pp 37-98). Mahwah, NJ: Lawrence Erlbaum.

Tall, D.O. (1995). Cognitive Growth in Elementary and Advanced Mathematical Thinking. In L. Meira and D. Carraher (Eds.), Proceedings of the $19^{\text {th }}$ Conference of the International Group for the Psychology of Mathematics Education, (Vol. 1, pp 61-75). Recife, Brazil: PME.

Tall, D.O., Thomas, M., Davis, G., Gray, E., and Simpson, A. (2000). What is the object of the encapsulation of a process? Journal of Mathematical Behavior, 18 (2), 1-19.

Van der Veer, R. and Valsiner, J. (1994). Reading Vygotsky: from fascination to construction. In R. van der Veer and J. Valsiner (Eds. and trans.), The Vygotsky Reader (pp 1-9). Oxford: Blackwell Publishers.

Vygotsky, L.S. (1981). The genesis of higher mental functions. In J.V. Wertsch (Ed.), The Concept of Activity in Soviet Psychology (pp144-188). Armonk, NY: M.E. Sharpe.

Vygotsky, L. S. (1934/1986). Thought and Language, A. Kozulin (Ed. and trans.), Cambridge, MA: MIT Press.

Wertsch, J.V. and Stone, C.A. (1985). The concept of internalisation in Vygotsky's account of the genesis of higher mental functions. In J.V. Wertsch (Ed.), Culture, Communication and Cognition (pp 162-179). New York: Cambridge University Press.

During the three years which I spent at Cambridge my time was wasted, as far as academical studies were concerned, as completely as at Edinburgh and at school. I attempted mathematics, and even went during the summer of 1828 with a private tutor (a very dull one) to Barmouth, but I got on very slowly. The work was repugnant to me, chiefly from my not being able to see any meaning in the early steps in algebra. This impatience was very foolish, and in after years I have deeply regretted that I did not proceed far enough at least to understand something of the great leading principles of mathematics; for men thus endowed seem to have an extra sense.

Charles Darwin (Autobiography) 